\title{
Autopercepção no Rorschach-SC de Idosos com Depressão em uma Perspectiva Idiográfica
}

\author{
Claudia Daiane Trentin Lampert ${ }^{1}$ \\ Silvana Alba Scortegagna ${ }^{2}$ \\ ${ }^{1}$ Universidade de Passo Fundo, RS, Brasil \\ https://orcid.org/0000-0002-5100-6459 \\ ${ }^{2}$ Universidade de Passo Fundo, RS, Brasil \\ https://orcid.org/0000-0002-4206-5916
}

\begin{abstract}
Resumo
O uso de instrumentos de autoexpressão pode trazer contribuições na apreensão do trabalho mental. Este estudo propõe avaliar a autopercepção no Rorschach-SC de idosos com depressão em uma perspectiva idiográfica. Foram analisados 31 protocolos de idosos entre 60 e 86 anos de idade, 29 mulheres e dois homens. A análise qualitativa contemplou respostas codificadas com conteúdo mórbido (MOR), Sombreado Vista (SumV), Representação Humana de Má qualidade (PHR) com qualidade formal distorcida (FQ-), e codificadas com PHR, Códigos Especiais (Sum6) e Códigos Especiais Críticos (WSum6). Os resultados demonstraram: a) respostas com MOR sugestivas de uma autoimagem negativa e desqualificada; b) respostas SumV indicando para autocritica e autoaversão; c) respostas PHR com FQ- sugerindo uma autopercepção distorcida e inadequada; e d) respostas de PHR com Sum6 e WSum6 reportando para alterações cognitivas e autoperceptivas. Os achados do Rorschach permitiram analisar configurações típicas de idosos com depressão e indicam perspectivas para o seguimento psicoterapêutico.

Palavras-chave: técnicas projetivas, avaliação psicológica, doenças crônicas, envelhecimento.
\end{abstract}

\section{Self-perception in the Rorschach-CS of the Elderly with Depression in a Idiographic Perspective}

\begin{abstract}
The use of self-expression can bring contributions to the apprehension of mental work. This study proposes to evaluate the self-perception in the Rorschach-SC of the elderly with depression in an idiographic perspective. Thirty-one protocols for the elderly between 60 and 86 years of age, 29 women and two men were analyzed. The qualitative analysis included morphic content (MOR), Shaded Vista (SumV), Poor Quality Human Representation (PHR) with distorted formal quality (FQ-), and coded with PHR, Special Codes (Sum6) and Critical Special Codes (WSum6). The results demonstrated: a) responses with MOR suggestive of a negative and disqualified self-image; B) SumV responses indicating for self-criticism and self-aversion; C) PHR responses with CF - suggesting distorted and inadequate self-perception; D) PHR responses with Sum6 and WSum6 reporting for cognitive and self-perceptual changes. The Rorschach findings allowed us to analyze typical configurations of elderly people with depression and indicate perspectives for psychotherapeutic.
\end{abstract}

Keywords: projective techniques, psychological assessment, chronic illness, aging. 


\section{Autopercepción en el Rorschach-SC de los Ancianos con Depresión en una Perspectiva Idiográfica}

\section{Resumen}

El uso de la herramientas de auto de expresión puede aportar contribuciones en la aprehensión de trabajo mental. Este estudio propone evaluar la autopercepción en el Rorschach SC de los ancianos con depresión desde una perspectiva idiográfica. Se analizaron 31 protocolos de edad entre 60 y 86 años de edad, 29 mujeres y dos hombres. El análisis cualitativo incluyó respuestas codificadas contenido mórbida (MOR), Shaded View (SumV), Representación humana de mala calidad (PHR) con distorsionada calidad formal (FQ-), con PHR, códigos especiales (SUMA6) y los códigos especiales críticos (WSum6). Los resultados mostraron: a) respuestas con MOR sugerente de una negativa del uno mismo - imagen y descalificados; b) SumV respuestas que indican para la auto-crítica y auto-odio; c) respuestas PHR con FQ- que sugiere una distorsionada e inadecuada auto - percepción; d) respuestas a PHR con SUMA6 y WSum6 refiriéndose a los cambios cognitivos y autoperceptivas. Los hallazgos del Rorschach permitieron analizar configuraciones típicas de ancianos con depresión e indican perspectivas para el seguimiento psicoterapéutico.

Palabras claves: técnicas proyectivas, evaluación psicológica, enfermidades crónicas, envejecimiento.

A depressão é uma das patologias de maior incidência associadas ao envelhecimento que traz consequências danosas à vida dos idosos. Conforme dados epidemiológicos, nas diferentes regiões do Brasil a prevalência de sintomas depressivos na população idosa varia entre $19 \%$ e 34\% (Borges, Benedetti, Xavier, \& D’Orsi, 2013), configurando-se como uma questão de saúde pública importante. Nessa população emergente, os quadros depressivos apresentam especificidades em relação a aspectos comportamentais, cognitivos e de personalidade.

As diversas alterações do envelhecimento quando acompanhadas por cognições de autocríticas negativas associam-se à diminuição da motivação, no senso de domínio e autoeficácia, e intensificam os sintomas depressivos. De modo inverso, percepção de autocontrole e autoestima são efeitos moderadores na depressão (Unüzter \& Park, 2012). Nos relacionamentos interpessoais, as percepções do apoio social são percebidas pelos idosos frequentemente como excessivas ou ineficientes, podem ser preditoras de problemas interpessoais familiares e com os cuidadores, e associam-se à etiologia e à manutenção da depressão (Taylor, 2014).

Em relação a características de personalidade, adultos mais velhos inflexíveis e menos abertos à experiência, quando confrontados com os eventos estressantes como limitações e lutos, podem apresentar pensamentos negativos, autocrítica, humor deprimido, resultando em um quadro depressivo (Fiske, Wetherell, \& Gatz, 2009).
Carneiro, Baptista e Moreno (2014) referem que indivíduos com depressão tendem a perceber a si mesmos de forma negativa com pensamentos recorrentes de inadequação, autocrítica e a apresentarem uma visão negativa das interações sociais, do mundo e do futuro. Tais percepções constituem-se fontes de vulnerabilidade para a ocorrência de sintomatologia e de transtornos depressivos, sendo importantes fatores a serem investigados (Carneiro et al., 2014; Smith, Haedtke, \& Shibley, 2015).

Diante da complexidade do transtorno depressivo em idosos, torna-se necessário recorrer a uma avaliação global que contemple tanto os aspectos sintomatológicos quanto os de personalidade. Para tanto, o uso de instrumentos psicológicos que possibilitem responder questões quanto à organização da estrutura da personalidade $\mathrm{e}$ aos seus aspectos psicodinâmicos, como o Método de Rorschach, pode ser uma boa opção.

Alguns estudos buscaram avaliar o funcionamento da personalidade de pacientes com depressão focalizando aspectos cognitivos, afetivos, autopercetivos e relacionais, com o uso do Método de Rorschach. No Brasil, Villemor-Amaral e Machado (2011) e Hisatugo e Yazigi (2014) investigaram os indicadores de depressão que compõem o Índice de Depressão (DEPI) do Rorschach no Sistema Compreensivo (Rorschach-SC), e evidenciaram diferenças significativas em variáveis afetivas e autoperceptivas, com prejuízos em indivíduos com depressão quando comparados a adultos sem depressão 
Com uma amostra composta somente por idosos, Lampert (2016) investigou a validade do Rorschach-SC para diferenciar indicadores de depressão. Participaram 75 idosos distribuídos em grupo clínico, com diagnóstico de depressão GC ( $n=36)$ e não clínico, sem diagnóstico de depressão GNC $(n=39)$. Entre os resultados, o GC apresentou aumento significativo nas variáveis respostas com distorções perceptivas (X-\%), somatório de Códigos Especiais Críticos (WSum6), respostas com conteúdo mórbido (MOR), somatório de respostas de Sombreado Vista (SumV), conteúdo humano parcial (Hd), respostas de Representação Humana de Boa qualidade (GHR) e menor que respostas de Representação Humana de Má qualidade (GHR < PHR), além de rebaixamento nas respostas com percepções comuns $(\mathrm{X}+\%)$, nas resposta com ajustamento perceptivo (XA\%), nas respostas de conteúdos humanos inteiros (H), Movimento Cooperativo (COP) e GHR quando comparados ao GNC. O Rorschach-SC mostrou-se um instrumento válido na avaliação da depressão em idosos.

No cenário internacional Hartmann, Halvorsen e Wang (2013) investigaram marcadores de vulnerabilidade para a depressão, em pacientes adultos com a enfermidade e sem a enfermidade. Os autores selecionaram um conjunto de variáveis cognitivas, afetivas e de enfrentamento do Rorschach-SC. Os resultados mostraram associação entre a depressão e os processos psicológicos que incluíam perturbações cognitivas, distúrbios afetivos e de enfrentamento.

Para além de estudos quantitativos, Verdon (2012) buscou avaliar a autorrepresentação de indivíduos entre 50 a 90 anos de idade, sem patologias psiquiátricas, por meio da análise qualitativa de 110 protocolos do Rorschach-SC. Os resultados mostraram que o envelhecimento pode ressaltar fragilidades na identidade, principalmente em organizações da personalidade borderline e narcisistas. Os protocolos de idosos que apresentaram essas estruturas foram marcados por respostas mórbidas, que denotaram uma intensa ferida narcísica como "pedaços de ferro-velho", "como quando o ferro está enferrujado", "ruína de uma torre, uma torre que está começando a cair aos pedaços", "botas velhas" e "sapatos cansados, velhos".

Verifica-se que as características de personalidade associadas a quadros psicopatológicos incluindo a depressão podem ser desencadeadoras de uma maior desorganização psíquica e fragilidades na autopercepção de idosos com esta enfermidade (Smith et al., 2015). Husain (2015) em estudo de caso de um paciente masculino, de 30 anos de idade, com diagnóstico de transtorno depressivo maior e sintomas de ideação paranoide e outras dificuldades psiquiátricas, analisou qualitativamente as respostas de conteúdos especiais no Rorschach. Para o autor, esta abordagem de avaliação de personalidade oferece um suporte para o uso alternativo desse instrumento psicológico, com base na teoria psicanalítica.

Com base no exposto, a análise das variáveis do Rorschach-SC, por meio interpretação quantitativa e nomotética aponta indicadores do funcionamento da personalidade em indivíduos com depressão e suscita questionamentos sobre a validade clínica desses achados. O conceito de validade clínica, trazido por Tavares (2003), contribui para a argumentação de que um dado extraído de um teste pode ser validado, com base em comparações entre resultados e observações, a partir de várias fontes.

Nessa perspectiva, a abordagem idiográfica por meio da análise qualitativa e interpretação de temas de conteúdo pode incrementar a exploração da riqueza e da dinâmica da personalidade (Weiner, 2000). A ideia principal aqui é de que as análises sob diversos prismas propiciam a compreensão de fenômenos psíquicos, para além do sintoma manifesto. Descrever uma mancha de tinta, pode permitir ao clínico entender melhor as necessidades do idoso, os seus conflitos ou desejos, e desempenhar um papel único para informar sobre as recomendações do tratamento. A apreciação temática de variáveis como conteúdos mórbidos e conteúdos humanos e representações humanas de boa ou má qualidade podem auxiliam no entendimento de aspectos autoperceptivos. Portanto, o objetivo deste estudo 
é avaliar a autopercepção no Rorschach-SC de idosos com depressão em uma perspectiva ideográfica.

\section{Método}

\section{Participantes}

Trata-se de um estudo clínico-qualitativo em que foram analisados 31 protocolos de idosos com depressão, com idades entre 60 a 86 anos, 29 mulheres e dois homens, de diferentes níveis socioeconômicos e escolaridades, procedentes de quatro unidades básicas de saúde, do interior do estado do Rio Grande do Sul. Os idosos participantes receberam diagnóstico médico de depressão, conforme critérios diagnósticos da Classificação Internacional de Doenças - CID-10 (Organização Mundial da Saúde [OMS], 1993); apresentavam sintomas depressivos atuais, verificados pela pontuação igual ou maior que 6 na Escala de Depressão Geriátrica - versão abreviada-GDS-15 (Sheikh \& Yesavage, 1986, adaptada por Almeida \& Almeida, 1999); não apresentavam indicativo de demência, averiguado pela pontuação igual ou maior que 20 pontos no Miniexame do Estado Mental (MEEM) (Bertolucci, Brucki, Campacci, \& Juliano, 1994; Brucki, Nitrini, Caramelli, Bertolucci, \& Okamoto, 2003). Desse modo, a amostragem foi por conveniência, não aleatória conforme critérios de inclusão e exclusão. Os critérios de inclusão levaram em conta: a) ausência de dificuldades visuais ou auditivas que pudessem interferir significativamente na aplicação do Rorschach-SC; b) não estar em tratamento devido à emergência de doenças neurodegenerativas e câncer. Os instrumentos para critérios de inclusão e exclusão (MEEM e GDS-15) foram aplicados previamente a coleta de dados pela autora deste artigo.

\section{Instrumentos}

\section{Questionário de caracterização sociodemográfica}

e de saúde. Elaborado pelas autoras, com o objetivo de obter informações sobre idade, gênero, situação conju- gal, de trabalho e de moradia, nível socioeconômico, escolaridade, e verificar os critérios de inclusão da amostra. O protocolo consistiu de 21 questões fechadas.

Rorschach no Sistema Compreensivo. (Exner, 2003, Exner, 1999; Exner \& Sendin, 1999). Consiste em um método de autoexpressão que avalia a organização e o funcionamento da personalidade. O instrumento é composto por 10 cartões com manchas de tinta simétricas. A sua aplicação consiste em mostrar um cartão de cada vez, e solicitar ao indivíduo que responda "o que isto poderia ser". Após a aplicação do teste, as respostas são codificadas considerando-se categorias de respostas, e análise quanto a frequências, proporções e razões, gerando os indicadores analisados para a intepretação e, ainda, incluiu a análise do conteúdo temático.

\section{Procedimentos}

Os dados foram obtidos do estudo prévio realizado por Lampert (2016) e perfizeram a análise de 31 protocolos de idosos com depressão. As variáveis selecionadas contemplaram os Conteúdos Mórbidos (MOR), respostas de Sombreado Vista (SumV), de conteúdo humano $[\mathrm{H},(\mathrm{H}), \mathrm{Hd},(\mathrm{Hd})]$ codificadas como o código especial Representação Humana de Má qualidade (PHR) e com qualidade formal distorcida (FQ-), e respostas codificadas com PHR, Códigos Especiais (Sum6) e Códigos Especiais Críticos (WSum6).

A análise idiográfica levou em conta as verbalizações das respostas, principalmente o uso de qualificativos que apontam para uma autoimagem denegrida, sentimentos de autocrítica e uma percepção de si mesmo e do outro de forma mais parcial e ilógica.

Este estudo obteve aprovação do Comitê de Ética em Pesquisa, sob parecer de número 849.201. Contempla os preceitos éticos do Psicólogo e a Resolução 466/12, do Conselho Nacional de Saúde CNS. 


\section{Resultados e discussão}

Para uma melhor visualização dos resultados, as tabelas apresentam o protocolo (Pr) e o número do cartão $(\mathrm{Cr})$ das respostas obtidas no método de Rorschach-SC. As Tabelas 1,2,3 e 4 expõem as respostas literais emitidas pelos idosos com depressão, codificadas com conteúdo mórbido (MOR), Sombreado Vista (SumV), Representação Humana de Má qualidade (PHR) com FQ-, e respostas codificadas com PHR, Códigos Especiais (Sum6) e Códigos Especiais Críticos (WSum6), respectivamente. A seguir, a Tabela 1 exibe as respostas de conteúdo MOR.
Como pode ser observado, os conteúdos das respostas MOR podem expressar dificuldades e sentimentos de desqualificação decorrentes do quadro depressivo, verbalizados como "corpo secando", "parece um tronco velho, que já não tem mais aquele verde, tá podre", "uma parte mais verde viva e a outra seca, envelhecida por causa da cor, menos viva", "flores secas, porque parecem que estão morrendo". Os conteúdos botânicos que recebem MOR sugerem isolamento social, pensamento pessimista e preocupações depressivas em relação à perda da integridade corporal e das capacidades funcionais (Weiner, 2000).

\section{Tabela 1}

Descrição das Respostas de Conteúdo MOR de Idosos com Depressão

\begin{tabular}{|c|c|c|}
\hline Pr & $\mathrm{Cr}$ & Resposta \\
\hline 7 & I & $\begin{array}{l}\text { 1-Morcego. Um morcego morto, é igual porque ele tá preto igual morto e tem pedacinhos podres caindo das asas } \\
\text { dele. }\end{array}$ \\
\hline 20 & I & $\begin{array}{l}\text { 1-É uma bruxa morta, aquelas borboletinhas pretas, é uma dessas. Tem o formato das asinhas, as antenas e é } \\
\text { preta, e tá morta. }\end{array}$ \\
\hline 11 & I & 2- Um cachorro. Tem o olhinho, patinha e rabo, ele tá aleijado, porque foi cortada uma orelha dele. \\
\hline 20 & II & $\begin{array}{l}\text { 2-Acho que é pulmões, tem um de cada lado. Dá impressão de ser o pulmão de gente que fuma porque está } \\
\text { preto e tá sangrando, tem sangue vermelho nele. Credo! Esse pulmão é de alguma que já vai morrer. }\end{array}$ \\
\hline 31 & II & $\begin{array}{l}\text { 2- Morcego. Agora ele está sangrando. Sangrando? Por causa das manchas vermelhas, é mesmo de antes, com } \\
\text { as asas, a cabeça e o corpo, mas ta sangrando. }\end{array}$ \\
\hline 7 & III & $\begin{array}{l}\text { 6- Dois macacos. Dois macacos que se suicidaram e estão mortos, de cabeça para baixo e com sangue, sangue } \\
\text { porque cai deles e é vermelho. }\end{array}$ \\
\hline 11 & III & 6- Dois bichos. Tem o biquinho, o corpo de bicho, mas o corpo tá todo separado, desmontado. \\
\hline 15 & III & $\begin{array}{l}\text { 7- Uma borboleta. Pelas asas, mas falta a cabeça e o rabo, quem sabe ela perdeu seus pedaços aqui do lado, } \\
\text { despedaçou, perdeu pedaços dela. }\end{array}$ \\
\hline 2 & IV & $\begin{array}{l}\text { 5- Parece um sapo defeituoso. Lá fora tinha uns sapos assim, parece defeituoso porque tem esse bico e nas } \\
\text { costas vem para o rabo comprido. }\end{array}$ \\
\hline 8 & IV & $\begin{array}{l}\text { 6- Uma cabeça, a garganta e o bigode. Parece com uma doença, como um câncer que comeu tudo. O câncer } \\
\text { comeu porque aqui tá estranho, parece doente. }\end{array}$ \\
\hline
\end{tabular}




\begin{tabular}{|c|c|c|}
\hline 09 & IV & $\begin{array}{l}\text { 6- Parece um monstro, sem cabeça. Tem os pés desse tamanho, os braços porque é monstro como aqueles que tu } \\
\text { vê na TV, isso que eu não assisto essas coisas. Tá sem cabeça porque tá esquartejado. }\end{array}$ \\
\hline 18 & IV & $\begin{array}{l}\text { 8- Um lobisomem. Porque é muito feio, o rosto dele, parece dois olhos, pernas embaixo, os braços, Feio? } \\
\text { Desfigurado, e esse pelo aqui, e ainda peludo. }\end{array}$ \\
\hline 20 & IV & $\begin{array}{l}\text { 8- Uma abelha, mas ela está morta. Pelo formato as asas e da cabecinha, mas como tá toda preta deve estar } \\
\text { morta. }\end{array}$ \\
\hline 28 & VI & $\begin{array}{l}\text { 10- Pode ser parte do corpo da gente, a coluna. Eu já fiz um exame e parece assim, o corpo tá secando, parece } \\
\text { que tá seco onde é mais escuro, como se doente. }\end{array}$ \\
\hline 29 & VII & 10- Esses são pedaços de animais. Porque parece a cara de animais, animais despedaçados, cortados. \\
\hline 26 & VII & $\begin{array}{l}\text { 13- Uma borboleta. Por causa das asas e o corpo dela, mas tá com asas muito grandes, feias e ela não vai poder } \\
\text { voar. }\end{array}$ \\
\hline 28 & VIII & $\begin{array}{l}\text { 12- Bichos subindo num tronco. Pela cor de pinheiro podre, branco e meio rosinha, o tronco parece um tronco } \\
\text { velho, porque tá escuro, já não tem mais aquele verde, tá podre. }\end{array}$ \\
\hline 8 & VIII & $\begin{array}{l}\text { 11- Um bicho. Tem a cabeça, um bico comprido e a asa está quebrada, tá quebrada porque parece que tá } \\
\text { desemedadas uma da outra, e aqui parece o pulmão do bicho. }\end{array}$ \\
\hline 02 & VIII & $\begin{array}{l}\text { 10- Tem dois bichos trepando numa árvore, são porco-espinho. Por causa da pata, as mãozinhas, rabo e a } \\
\text { cabeça, a arvore parece galhos uma parte mais verde viva e a outra seca, envelhecida por causa da cor, menos } \\
\text { viva, e os bichos tão trepando na arvore e se apoiando no chão. }\end{array}$ \\
\hline 27 & IX & $\begin{array}{l}\text { 12- Uma madeira. Por causa que na roça são muitos pedaços de madeira, e tem a parte mais escura e suja, um } \\
\text { verde feio e sujo. }\end{array}$ \\
\hline 30 & IX & $\begin{array}{l}\text { 16- Árvore. Tem as folhas e o tronco, as folhas estão secas, amarelando, morrendo, e a parte verde tá viva e } \\
\text { esses vermelhos são as frutas. }\end{array}$ \\
\hline 08 & IX & $\begin{array}{l}\text { 13- Nossa! É uma gota de sangue, uma emendada na outra. Gota de sangue, o esqueleto, pode ser um bicho } \\
\text { machucado porque tá pingando sangue, tá baleado, e tem uma boca aqui. }\end{array}$ \\
\hline 14 & IX & $\begin{array}{l}\text { 11- Parecido com um furacão vermelho, preto e laranja. As manchas vermelhas, cinza e alaranjado, ele tá } \\
\text { subindo alguma coisa, vai puxando e destruindo as coisas para cima, parece tudo destruído. }\end{array}$ \\
\hline 20 & $\mathrm{X}$ & $\begin{array}{l}\text { 14- Esses são dois demônios mortos babando. Tem a cabeça e o corpo, só que eles estão babando igual aos } \\
\text { mortos, porque tem a cabeça pra baixo como mortos e a baba azul clara saindo da boca. }\end{array}$ \\
\hline 30 & $\mathrm{X}$ & 18- Flores. Tem umas amarelas e outras secas, porque parecem que estão morrendo. \\
\hline 25 & $\mathrm{X}$ & $\begin{array}{l}\text { 15- Um bicho morto. Ele está todo roído, não sei que bicho é, mas ele esta todo roído e tá caído por isso parece } \\
\text { morto }\end{array}$ \\
\hline 10 & $\mathrm{X}$ & $\begin{array}{l}\text { 13- Dois fetos mortos. São fetos porque ainda não tem o formato do corpo direito, tem só a cabeça e o corpo, } \\
\text { sem os braços e pernas. Parecem mortos porque estão babando, tá escorrendo da boca deles. }\end{array}$ \\
\hline
\end{tabular}

Fonte: Elaborada pelas autoras 
A percepção de uma autoimagem negativa e desqualificada, trazida nos protocolos pelos idosos deste estudo, sugere fragilidade narcísica, como também evidenciado no estudo de Verdon (2012). Tal percepção pode ser potencializada pelos pensamentos negativistas de desvalorização, interpretação negativa de si mesmo, do ambiente e do futuro, inerentes à dinâmica psíquica da depressão (Carneiro et al., 2014; Smith et al., 2015). Notadamente, isso pode ser observado nas respostas MOR que representam uma autoimagem danificada ilustrada nas narrativas "aleijado", "desmontado", "feio", "defeituoso", "desemedado", "doente" e "cortado". Algumas verbalizações dos idosos estão mais associadas à autoimagem negativa, à percepção denegrida de si mesmo como, "podre", "pedacinhos podres caindo", "esquartejado" e "desfigurado".

A autoimagem negativa associada a atitudes de desqualificação e autoaversão podem ser relacionadas à depressão e potencial suicida (Weiner, 2000). Ratificam essa proposição as expressões "morcego morto", "bruxa morta", "abelha morta", "pulmão de alguém que já vai morrer", "parece tudo destruído", "demônios mortos babando", "bicho morto, está todo roído e tá caído por isso parece morto", "dois fetos mortos", "dois macacos que se suicidaram e estão mortos". Essas respostas sugerem autopercepção vulnerável e a iminência de desintegração do ego. Tais achados corroboram Husain (2015) que encontrou autorrepresentação danificada em um homem com depressão grave, e destacou a narrativa no cartão IV, "um animal aberto... como uma pele de animal, como um castor que foi aberto, a barriga no chão...”. O animal danificado situa-se no chão, em uma posição particularmente submissa. A presença de autoimagem disfórica, observada nas respostas MOR e SumV, reafirmam para Weiner (2000) a suscetibilidade a episódios de depressão. Sendo assim, a Tabela 2 descreve as respostas de SumV de idosos com depressão.

\section{Tabela 2}

Descrição das Respostas de SumV de Idosos com Depressão

\begin{tabular}{|c|c|c|}
\hline $\mathbf{P r}$ & $\mathrm{Cr}$ & Respostas \\
\hline 20 & II & 3.Aqui tem um coração. Parece por que é igual tem as voltinhas, arredondadas onde tem o mais vermelho. \\
\hline 15 & II & $\begin{array}{l}\text { 3- Parece um lago e uma escadaria que sai da igreja, um pátio, uma torre. Porque aqui a escadaria é os degraus porque tá mais } \\
\text { branquinho e mais pretinho, dá a impressão de degrau, mais alto e mais baixo, parece os níveis dos degraus. O lago o branco, } \\
\text { ai tem a escadaria que vai ate a torre da igreja, o formato da igreja. }\end{array}$ \\
\hline 15 & III & $\begin{array}{l}\text { 6-Duas pessoas agachadas pegando alguma coisa embaixo, essa fonte de agua tá correndo, pegando algo embaixo das } \\
\text { pessoas. Fonte correndo agua aqui no meio, por causa dessa parte mais escura é a agua e até parece que tem as ondinhas, as } \\
\text { voltinhas das ondinhas, fez como um buraco mais fundo, parece que tá correndo agua. E as pessoas agachadas são narigudas, } \\
\text { um mordomo de avental branco, estando pegando algo para usar, tão levantando. }\end{array}$ \\
\hline 19 & IV & 9- Duas orelhas de animais, de cachorro. A forma, caidinha para baixo, parte mais escura parece mais saliente mais pra fora. \\
\hline 05 & VI & $\begin{array}{l}\text { 13- parece um poste, isso parece os fiozinhos. É bem parecido, pelos fiozinhos, porque é alto, parece que está na terra, } \\
\text { plantado no meio da terra, parece uma parte mais funda e firme, essa diferença aqui na cinza, parece que tá fincado na terra. }\end{array}$ \\
\hline 14 & VI & $\begin{array}{l}\text { 6- Parecido com aqueles foguetes que vão para a lua. Porque ele tá em cima, para ir para a lua, sai daqui de baixo, tem um } \\
\text { risco, na parte mais escurinha no meio que ele deixou marcado quando saiu. O risco é essa parte aqui no meio, o caminho que } \\
\text { ele fez ficou marcado. }\end{array}$ \\
\hline
\end{tabular}




\begin{tabular}{|l|l|l|}
\hline 17 & VI & $\begin{array}{l}\text { 7-Ai Jesus! Parece pedra, um tronco colocado, um palanque. Um palanque colocado nesse tronco ou pedra, o palanque dentro } \\
\text { da pedra. O palanque da a impressão de estar afundado dentro da pedra, nessa parte do meio com a diferença do cinza, aqui é } \\
\text { onde o palanque entra na pedra. }\end{array}$ \\
\hline 06 & VIII & $\begin{array}{l}\text { 11- Um coração. Por causa das voltas, redondo como as voltas do coração, parte mais escura e as voltas, a parte de dentro da } \\
\text { volta, é igual ao coração. }\end{array}$ \\
\hline 14 & $\mathrm{X}$ & $\begin{array}{l}\text { 14- Pulmão. Aquele que a gente mata os bichos e tem do lado e do outro, é mais esbranquiçado e vermelho, mais rosa } \\
\text { e depois mais vermelho e parece que aqui vai entrando pra dentro do pulmão, indo para dentro quanto mais fundo mais } \\
\text { vermelho mais forte }\end{array}$ \\
\hline 27 & $\mathrm{X}$ & $\begin{array}{l}\text { 14- Um enfeite de parede. Essa é a flor, e tem um vaso que segura aqui. Achei que ficava bonito, que é um ramo e aqui volta } \\
\text { uma flor e outra flor e duas flores amarelas e tem o vaso? Que segura o enfeite, isso (o enfeite) é uma coisa que colocaram } \\
\text { dentro do vaso, a flor parece estar mais pra dentro do vaso, onde a cor fica diferente é onde ela tá mais para dentro. }\end{array}$ \\
\hline
\end{tabular}

Fonte: Elaborada pelas autoras

Na Tabela 2 verifica-se a constância de sentimentos de autocrítica e autoaversão dos idosos em relação a si mesmos em expressões "fincado na terra", "deixou marcado, mais fundo quando saiu", "vai entrando pra dentro do pulmão", "degrau mais baixo e mais alto", "fazer um buraco mais fundo", "impressão de estar afundado na pedra" e "estar mais para dentro". Esses resultados apoiam estudos (Hisatugo \& Yazigi, 2014; Villemor-Amaral \& Machado, 2011) que demonstraram aumento de respostas de SumV em indivíduos com depressão, sugerindo presença de sofrimento emocional e ruminações depressivas. A Tabela 3 apresenta as respostas de conteúdos humanos $[\mathrm{H},(\mathrm{H}), \mathrm{Hd},(\mathrm{Hd})]$ codificadas como Representação Humana de Má qualidade (PHR) de acordo com o critério de resposta com qualidade formal distorcida (FQ-).
Na Tabela 3, a associação entre respostas de representação humana e FQ- indica autopercepção distorcida e inadequada (Weiner, 2000). As expressões "bracinhos pequenos", "pessoas lutando mas com as mãos juntas, amarradas", "pessoas com gorro na cabeça", "pessoas tão pegando uma fruta, mas tem formigas em cima", "uma mulher, mas só tem a parte de cima, metade dela" sugerem que os idosos deste estudo percebem a si mesmos como impotentes e com recursos psíquicos limitados para obter satisfação no ambiente. Algumas verbalizações denotam o uso da fantasia e expressam autopercepção negativa e destrutiva, notadamente nas respostas "uma pessoa de poder que jogou poderes, parece que ele jogou os bichos e daí saiu sangue”, "um demônio, com cabeça no lugar do rabo, a cabeça dele é ao contrário" e "dois demônios pequenos se olhando,

\section{Tabela 3}

Descrição das Respostas de PHR com FQ-de Idosos com Depressão

\begin{tabular}{|l|l|l|}
\hline \multicolumn{1}{|c|}{ Pr } & \multicolumn{1}{|c|}{ Cr } & \\
\hline 25 & I & 2- Duas pessoas. Tem a cabeça, corpo e dois bracinhos pequenos. \\
\hline 15 & I & $\begin{array}{l}\text { 2- Parece alguém com poder, que chegou fazendo alguma proeza. uma pessoa de poder que jogou poderes, sai bichos } \\
\text { das mãos que ele jogou, tem sangue, parece que ele jogou os bichos e dai saiu sangue (...) esses pontinhos espalhados, } \\
\text { parece aquelas pessoas que você vê nos desenhos que tem poder fazem assim com as mãos e sai aquele poder. }\end{array}$ \\
\hline
\end{tabular}




\begin{tabular}{|c|c|c|}
\hline 12 & II & $\begin{array}{l}\text { 2- Duas pessoas lutando. São pessoas por causa da cabeça, as mãos, a forma das mãos. Eles estão com as mãos } \\
\text { juntas, amarradas, porque parece um barbante ao redor, um barbante amarrado. Parece que estão lutando para se } \\
\text { soltar. }\end{array}$ \\
\hline 23 & II & $\begin{array}{l}\text { 3-No olho... parece nessas manchas pretas, parece ursos.. não, são pessoas. Parece duas pessoas, um com a mão no } \\
\text { outro, pelo tamanho, pela maneira e tem os pés embaixo. }\end{array}$ \\
\hline 23 & II & 4-Duas pessoas com gorro na cabeça. Porque o formato do rosto, as pernas, e a toca? É o formato e está na cabeça. \\
\hline 08 & III & $\begin{array}{l}\text { 5- dois esqueletos, estão de sapato de salto e de bunda empinada e as duas mãos dadas. Esqueletos porque estão de } \\
\text { sapato de salto, tem cabeça. }\end{array}$ \\
\hline 20 & IV & $\begin{array}{l}\text { 6- Um demônio. Têm os chifres, os pés grandes, os braços pequenos e tem a cabeça no lugar do rabo, a cabeça dele é } \\
\text { ao contrário. }\end{array}$ \\
\hline 1 & $\mathrm{~V}$ & 8-Uma pessoa porque tem os pés. Notei como se fossem os pés e o corpo, tirando do lado. \\
\hline 11 & VI & 9- Gêmeos que nasceram grudados. Estão de costas grudados por essa parte, grudados nas costelas. \\
\hline 27 & VII & $\begin{array}{l}\text { 8-Uma mulher, só a parte de cima, metade dela, debaixo dos braços. A parte da bunda, os braços aqui, os } \\
\text { quadris e embaixo dos braços, pra cima deve ter a cabeça, parece a parte de baixo dos braços porque ela tá assim (fez } \\
\text { o movimento levantando os braços) o braço sobre pra cima. }\end{array}$ \\
\hline 09 & IX & $\begin{array}{l}\text { 12- Representa as pessoas pegando alguma coisa. As pessoas tão pegando uma fruta, tem as formigas em cima. } \\
\text { Porque estão em pé, com as mãos pegando a fruta e aqui parece uma formiga cheia de perninhas porque é o formato } \\
\text { de um mamão, no mamão estão as formigas. }\end{array}$ \\
\hline 20 & IX & $\begin{array}{l}\text { 13- Dois demônios pequenos se olhando. Tem a cabeça, o pescoçinho e o corpo. Eles são feios e tem a mesma cor dos } \\
\text { cachorros, vermelhos são demoninhos cor de fogo. }\end{array}$ \\
\hline 22 & $X$ & $\begin{array}{l}\text { 15- Uma pessoa, que está com um negócio na cabeça. -as pernas e o corpo, parece uma lâmpada na cabeça, como no } \\
\text { filme, tem o rosto, o cabelo no mais escuro, cabelo escuro. }\end{array}$ \\
\hline
\end{tabular}

Fonte: Elaborada pelas autoras

eles são feios e têm a mesma cor dos cachorros". As análises desses conteúdos propõem alterações cognitivas e autoperceptivas nos idosos deste estudo, e ratificam os achados empíricos encontrados em indivíduos com depressão (Carneiro et al., 2014; Hartmann et al., 2013; Smith et al., 2015). Destaca-se, a seguir, a presença de respostas PHR codificadas com Sum6 como MOR, Movimento Agressivo (AG) e Perseveração (PSV) e WSum6 como Combinação Incongruente (INCOM), Combinação Fabulada (FABCOM), Lógica Inadequada (ALOG) e Contaminação (CONTAM), apresentadas na Tabela 4.

\section{Tabela 4}

Descrição das Respostas de PHR, MOR, AG, PSV, INCOM, FABCOM, ALOG, CONTAM de Idosos com Depressão

\begin{tabular}{|l|l|l|}
\hline \multicolumn{1}{|c|}{$\mathbf{P r}$} & Cr & \multicolumn{1}{c|}{ Respostas } \\
\hline 14 & II & $\begin{array}{l}\text { 2- Dois ratinhos que estão com as mãos juntas. São ratos por causa das orelhas e as perninhas. Parece que eles } \\
\text { estão brigando, porque estão com as mãos assim (posição das mãos). }\end{array}$ \\
\hline
\end{tabular}




\begin{tabular}{|c|c|c|}
\hline 15 & II & $\begin{array}{l}\text { 4- Dois lutadores, ursos lutando. Por causa do pé levantado, o outro tá escondido e usando as mãos para se } \\
\text { bater. Pé escondido? É pela posição de luta, tá com a perna dobrada e dai o pé fica escondido aqui atrás dele, } \\
\text { do corpo dele. }\end{array}$ \\
\hline 21 & II & $\begin{array}{l}\text { 3- Dois ursinhos. Os ursinhos pintadinhos tem o vermelho no meio que parece sangue, estão brigando o } \\
\text { sangue porque se machucaram. }\end{array}$ \\
\hline 07 & III & 4- Duas pessoas. Tem a cabeça, o pescoço, as pernas, mas eles tem pernas de bicho do mato e não de pessoas. \\
\hline 24 & III & 4- Uma perna com sapato. Por causa do salto, e a perna está dobrada. \\
\hline 03 & III & 5- Uma perna humana. Por causa do sapato de salto. \\
\hline 18 & IV & $\begin{array}{l}\text { 8-Um lobisomem. Porque é muito feio, o rosto dele, parece dois olhos, pernas embaixo, os braços. Feio? É esse } \\
\text { pelo aqui, é peludo (passa a mão na prancha. }\end{array}$ \\
\hline 08 & IV & $\begin{array}{l}\text { 6- Uma cabeça, a garganta e o bigode. Parece com uma doença, como um câncer que comeu tudo. O câncer } \\
\text { comeu porque aqui tá estranho, parece doente. }\end{array}$ \\
\hline 07 & VI & $\begin{array}{l}\text { 9- Um homem. Ele está apontando uma pistola, tem só a mão do homem, parece porque tem o mesmo formato de mão } \\
\text { e de pistola. Aqui tem dois vigilantes um em cada ponta com armas cuidando pra matar o outro homem com a pistola. }\end{array}$ \\
\hline 27 & VI & 7- Criatura do céu! Que é isso! Parece as costas e a coluna. Por causa de ser tão reto e do lado tem o corpo. \\
\hline 09 & VII & $\begin{array}{l}\text { 9- Uma nuvem, uma cabeças em cima da nuvem. Tipo uma nuvem, tem o repartido no meio e pros lados, } \\
\text { parece o rosto de uma pessoa, elas estão em cima da nuvem. }\end{array}$ \\
\hline 13 & VII & 10- Duas bocas. Parece que querem se morder, estão viradas uma para a outra e querem se morder. \\
\hline 15 & VII & $\begin{array}{l}\text { 12-Parece dois gnomos, estão fazendo assim, em cima de uma borboleta grande. eles tem boca, olhos, cabelos, } \\
\text { é um casal de gnomos (...) porque são pequeninhos e estão fazendo assim com a mão, estão de pé em cima de } \\
\text { uma borboleta, estão fazendo assim com a mão para se equilibrar. }\end{array}$ \\
\hline 18 & VII & $\begin{array}{l}\text { 11-Essa eu não sei...Um bicho, dois são iguais. Muito esquisito, esse aqui pela boca, parece uma testa de } \\
\text { pessoa, cabelo pra cima, uma trança, trança? Parece ser cabelo porque é a continuação da cabeça. Parece } \\
\text { pessoas? É as duas coisas bicho com pessoa, tá esquisito. }\end{array}$ \\
\hline 24 & VIII & $\begin{array}{l}\text { 10-Uma raposa, ela tá tentando subir no braço de uma pessoa. Por causa do braço e ela tá assim (estendendo } \\
\text { as mãos pra ela subir) (...) Por causa das patas. }\end{array}$ \\
\hline 16 & IX & 16- Besouros. Tem as patas, as antenas e garras afiadas, estão indo um contra o outro para brigar. \\
\hline 20 & $\mathrm{X}$ & $\begin{array}{l}\text { 14- Esses são dois demônios mortos babando. Tem a cabeça e o corpo, só que eles estão babando igual aos } \\
\text { mortos, porque tem a cabeça pra baixo como mortos e a baba azul clara saindo da boca. }\end{array}$ \\
\hline 10 & $\mathrm{X}$ & $\begin{array}{l}\text { 13- Dois fetos mortos. São fetos porque ainda não tem o formato do corpo direito, tem só a cabeça e o corpo, } \\
\text { sem os braços e pernas. Mortos? Parecem mortos porque estão babando , tá escorrendo da boca deles. }\end{array}$ \\
\hline 26 & $\mathrm{X}$ & $\begin{array}{l}\text { 16- É um corpo humano, não sei explicar como. Acho que é só os pedaços do corpo humanos, Pulmão do lado } \\
\text { do osso, pelo jeito dos rins, o fio da coluna, o formato do tronco. }\end{array}$ \\
\hline 13 & $\mathrm{X}$ & $\begin{array}{l}\text { 14- Uma pessoa com um boné na cabeça. Porque é alto, tem perna e braço, está de boné por causa do sol, e } \\
\text { porque é alto, querem encontrar alguma coisa para comer. }\end{array}$ \\
\hline
\end{tabular}

Fonte: Elaborada pelas autoras 
As respostas descritas na Tabela 4, que incluem as expressões "pessoas com pernas de bicho do mato", "cabeças em cima de nuvens", "mortos babando", "as duas coisas, bicho com pessoa", sugerem que os idosos deste estudo apresentam pensamento ilógico e incoerente acerca das percepções de si mesmos e dos outros, formulam ideias dissociadas sobre a autopercepção e a percepção do outro, o que agrava as dificuldades de ajustamento psicológico nos quadros depressivos (Weiner, 2000). Os conteúdos humanos parciais associados à distorção da forma, constatados nas respostas "parece as costas e coluna, e do lado o corpo", "perna com sapato", "duas bocas que querem se morder" e "cabeça, a garganta e o bigode, parece com uma doença, um câncer que comeu tudo" podem indicar desconforto e dificuldade de integração do eu, resultando uma visão parcial de si mesmo e do outro (Exner \& Sendin, 1999; Weiner, 2000).

Nota-se uma percepção distorcida e danificada de si mesmo, averiguada nas respostas PHR com FQ- e MOR. Soma-se a isso, a presença de conteúdos agressivos como "bocas que querem se morder", "besouros indo um contra o outro para brigar", "ratinhos que parecem que estão brigando", "vigilantes um em cada ponta com armas cuidando pra matar o outro homem com a pistola" e "duas pessoas lutando" reveladores de sentimentos de agressividade e hostilidade que podem, ainda, indicar dificuldades interpessoais e a presença de conflitos (Exner, 2003). Tais características legitimam os estudos sobre os idosos com depressão e associam-se aos sintomas de isolamento social (Smith et al., 2015, Taylor, 2014). Considerando a presença de uma autoimagem e de uma autocrítica negativa, a percepção distorcida de si mesmo, as respostas de hostilidade e de morbidade emitidas pelos idosos podem ser indicativos de sentimentos de autoagressão e punição.

Ao avaliar a autopercepção no Rorschach-SC de idosos com depressão em uma perspectiva ideográfica, este estudo trouxe importantes contribuições. Pode-se verificar que: a) as verbalizações das respostas MOR nos idosos com depressão sugerem sentimentos de desqualificação, pensamento pessimista e preocupações depressivas em relação à perda da integridade corporal e das capacidades funcionais, e podem relacionar-se a fragilidade narcísica e dinâmica psíquica presente na depressão; b) a constância de sentimentos de autocrítica e autoaversão dos idosos em relação a si mesmos, verificadas nas respostas SumV, sugerem presença de sofrimento emocional; c) a associação de respostas PHR e presença de Hd com FQ- são sugestivas de uma autopercepção distorcida, inadequada e com dificuldade de integração do eu; e d) a presença de Sum6 e WSum6 em respostas com PHR reportam para pensamentos ilógicos e incoerentes, com ideias dissociadas sobre a autopercepção, aludindo para alterações cognitivas e autoperceptivas nos idosos com depressão.

Tais elementos ilustram a estrutura e a dinâmica psíquica de idosos com depressão e apoiam estudos prévios que indicam à utilidade do Rorschach tanto em procedimentos de avaliação quanto no suporte terapêutico mais efetivo, que deve ser dirigido a eles. Por fim, embora a abordagem idiográfica não possa servir para generalizações, esses resultados podem ser úteis como sinalizadores para melhor compreensão dos estados emocionais de idosos com depressão, para responder de modo mais efetivo às demandas de auxílio profissional, e para incrementar a compreensão dos achados quantitativos. Seguramente as investigações devem prosseguir, principalmente com o incremento de idosos do gênero masculino, pouco expressiva na amostra deste estudo. Tais pesquisas poderão expandir o processo de investigação e de conhecimento com o uso do Rorschach neste contexto, ainda pouco explorada.

\section{Referências}

Almeida, O. P., \& Almeida, S. A. (1999). Confiabilidade da versão brasileira da Escala de Depressão Geriátrica (GDS) versão reduzida. [Reliability of the Brazilian version of the geriatric depression scale (GDS) short form]. Arquivos de Neuropsiquiatria, 57(2B), 421-426. doi: https://dx.doi.org/10.1590/S0004-282X1999000300013 
Bertolucci, P. H. F., Brucki, S.M.D., Campacci, S.R., \& Juliano, Y. (1994). O Miniexame do estado mental em uma população geral: impacto da escolaridade. [The Mini-Mental State Examination in an outpatient population: influence of literacy]. Arquivos de NeuroPsiquiatria, 52(1) 1-7. Retrieved from http://www. scielo.br/pdf/anp/v52n1/01.pdf https://doi.org/10.1590/ s0004-282x1994000100001

Borges, L. J., Benedetti, T. R. B., Xavier, A. J., \& D’Orsi, E. (2013). Fatores associados aos

sintomas depressivos em idosos: estudo EpiFloripa. [Associated factors of depressive symptoms in the elderly: Epi Floripa study]. Revista de Saúde Pública, 47(4), 701-710. doi:10.1590/S0034-8910.2013047003844

Brucki, S. M. D. I., Nitrini, R., Caramelli, P., Bertolucci, P., \& Okamoto, I.H. (2003). Sugestões para o uso do Miniexame do Estado Mental no Brasil. [Suggestions for utilization of the mini-mental state examination in Brazil]. Arquivos de Neuro-Psiquiatria, 61(3B), 777-781. doi: https://dx.doi.org/10.1590/S0004-282X2003000500014

Carneiro, A. M., Baptista, M. N. \& Moreno, R. A. (2014). Depression thoughts scale: association with depression rating scales. Journal Depression \& Anxiety, 3(3), 155. doi:10.4172/2167-1044.1000155

Exner, JR, J. E. (2003). The Rorschach: A comprehensive system. (4. ed.). New York, NY: John Wiley \& Sons.

Exner JR, J.E. (1999). Manual de classificação do Rorschach para o sistema compreensivo. São Paulo, SP: Casa do Psicólogo.

Exner JR., J. E. \& Sendin, C. (1999). Manual de interpretação do Rorschach para o sistema compreensivo. São Paulo, SP: Casa do Psicólogo.

Fiske, A., Wetherell, J. L, \& Gatz, M. (2009). Depression in older adults. Annual Review Clinnical Psychology. 5, 363-389. doi. http://dx.doi.org/10.1146/annurev.clinpsy. 032408.153621

Hartmann, E., Halvorsen, M., \& Wang, C.E.A. (2013). Rorschach variables and dysfunctional attitudes as measures of depressive vulnerability: a 9-year follow-up study of individual with different histories of Major Depressive Episodes. Journal of Personality Assessment, 95(1), 26-37. doi: 10.1080 / 00223891.2012 .713881$.

Hisatugo, C. L. C., \& Yazigi, L. (2014). Estudo exploratório com indivíduos com depressão por meio do Rorschach,
Sistema Compreensivo. Avaliação Psicológica, 13(2), 157166. https://doi.org/10.11606/t.47.2008.tde-28012009-094602

Husain, O. (2015). From persecution to depression: A case of chronic depression: associating the Rorschach, the TAT, and Winnicott. Journal of Personality Assessment, 97(3), 230-240. doi. 10.1080/00223891.2015.1009081

Lampert, C. D. T (2016). Evidências de validade do Rorschach no diagnóstico de depressão em idosos. [Evidences of Rorschach validity in the diagnosis of depression in elderly] (Dissertação de mestrado). Retrieved from https://secure.upf.br/tede/tde_busca/index.php

Organização Mundial da Saúde [OMS] (1993). CID-10: Classificação de Transtornos Mentais e de Comportamento. Descrições clínicas e diretrizes diagnósticas. Porto Alegre: Artes Médicas. https://doi. org/10.1590/s1516-44461999000200014

Sheikh, J. I., \& Yesavage, J. A. (1986). Geriatric Depression Scale (GDS): Recent evidence and development of a shorter version. Clinical Gerontology, 5, 165-173. https://doi.org/10.1300/j018v05n01_09

Smith, M., Haedtke, C., \& Shibley, D. (2015). Late life depression detection: an evidence-based guideline. Journal Gerontolical Nursing, 41(2), 18-25. doi:10.3928/00989134-20150115-99.

Tavares, M. (2003). Validade Clínica. Psico-USF, 8(2), 125-136. doi:10.1590/S1413-82712003000200004

Taylor, W. D. (2014). Depression in the elderly. The New England Journal of Medicine, 371, 1228-1236.

Unützer, J., \& Park, M. (2012). Older adults with severe, treatment-resistant depression. The Journal of the American Medical Association, 308(9), 909-918. doi: 10.1001/2012.jama.10690.

Verdon, B. (2012). Changing while remaining the same self-representation confronted with aging. Rorschachiana, 33, 145-168. doi: 10.1027/1192-5604/a000033

Villemor-Amaral, A. E., \& Machado, M. A. S. (2011). Indicadores de depressão do Zulliger no Sistema Compreensivo (ZSC). [The depression index in the Zulliger Comprehensive System (ZSC)]. Paidéia, 21(48), 21-27. doi: http://dx.doi.org/10.1590/S0103863X2011000100004

Weiner, I. B. (2000). Princípios da interpretação do Rorschach. São Paulo: Casa do Psicólogo. 
Endereço para correspondência: Claudia Daiane

Trentin Lampert ( Br 285, Bairro São José, Passo

Fundo, Rio Grande do Sul, 99052-900; 5499917

2002; trentin_rs@yahoo.com.br).

Recebido em: 7/2/2018.

Aprovado em: 8/4/2019.

Publicado em: xx/xx/2019.

\section{Claudia Daiane Trentin Lampert}

E-mail: trentin_rs@yahoo.com.br

Titulação Acadêmica: Mestre em Envelhecimento

Humano UPF

Afiliação Institucional: Universidade de Passo

Fundo, Passo Fundo, RS, Brasil

\section{Silvana Alba Scortegagna}

E-mail: silvanalba@upf.com.br

Titulação Acadêmica: Doutora em Psicologia

Universidade de São Francisco

Afiliação Institucional: Universidade de Passo

Fundo, Passo Fundo, RS, Brasil 